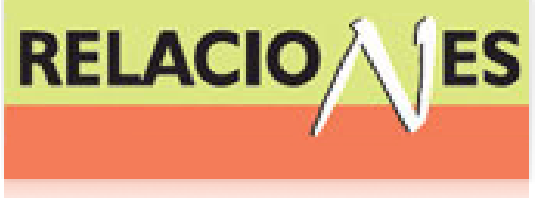

Relaciones. Estudios de historia y sociedad ISSN: 0185-3929

relacion@colmich.edu.mx

El Colegio de Michoacán, A.C

México

García Tello, Diana Patricia

La espacialidad de los indígenas en el área metropolitana de Monterrey

Relaciones. Estudios de historia y sociedad, vol. XXXIV, núm. 134, 2013, pp. 57-92

El Colegio de Michoacán, A.C

Zamora, México

Disponible en: http://www.redalyc.org/articulo.oa?id=13726972003

Cómo citar el artículo

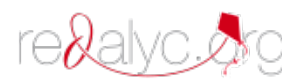

- Número completo

- Más información del artículo

- Página de la revista en redalyc.org

Sistema de Información Científica

Red de Revistas Científicas de América Latina, el Caribe, España y Portugal Proyecto académico sin fines de lucro, desarrollado bajo la iniciativa de acceso abierto 


\title{
La espacialidad de los indígenas en el área metropolitana de Monterrey
}

\author{
Diana Patricia García Tello*
}

UNAM-INSTITUTO DE GEOGRAFÍA

El presente artículo analiza, desde una perspectiva geográfica, la construcción de una espacialidad indígena en el área metropolitana de Monterrey, destacando las relaciones sociales entre los indígenas y una determinada esfera de agentes sociales responsables de la visibilidad de los indígenas en la urbe regia. Asimismo, se puntualizan las acciones, hechos e iniciativas de ley en atención y apoyo a dicho sector, con la finalidad de analizar cómo a través de estos elementos se han organizado los indígenas en el área metropolitana.

(Espacialidad, identidad, visibilidad, indígenas, área metropolitana de Monterrey)

\section{INTRODUCCIÓN}

$\mathrm{n}$ recientes fechas, el estado de Nuevo León y en particular los municipios que conforman el área metropolitana ${ }^{1}$ se convirtieron en nuevas zonas de destino por parte de indígenas provenientes de distintos puntos del país como San Luis Potosí (tenek, nahuas), Querétaro (otomíes), Oaxaca (mixtecos, triquis), Veracruz (nahuas), entre otros. El área metropolitana de Monterrey ${ }^{2}$

*dianatello@hotmail.com

${ }^{1}$ Apodaca, García, Escobedo, Guadalupe, Juárez, Monterrey, Santa Catarina, San Nicolás de los Garza y San Pedro Garza García.

${ }^{2}$ El área metropolitana incluye una o más ciudades de 50,000 habitantes que constituyen una unidad económica integrada con amplio volumen de viajes y comunicaciones diarios entre la ciudad o ciudades centrales y los espacios exteriores del área (Mayer y Kohn 1959). 
(AMM) no se caracterizaba por la presencia de grupos indígenas originarios de la región. Sin embargo, en los noventa del siglo xx, la migración y el continuo crecimiento de la población indígena llaman la atención de la sociedad regiomontana. Debido al contexto político, social y económico del país que impactó directamente en las zonas rurales, la movilidad espacial de los indígenas hacia los centros urbanos se convirtió en una de las pocas opciones para sobrevivir (Granados 2005). En los setenta, el AMM se vuelve foco de atracción por su crecimiento económico y expansión urbana (véanse mapas 1 y 2). Los sectores industrial y de servicios fueron nichos de oportunidad laboral para los migrantes, en especial, indígenas (en su mayoría nahuas y tenek) provenientes de distintos municipios y localidades de San Luis Potosí (Durin 2008). Pronto, otros grupos indígenas llegaron al área metropolitana en busca de trabajo, insertándose en el comercio informal, practicando la venta ambulante de artesanías, bisutería, dulces, semillas o bien pidiendo dinero en las avenidas y calles, ejemplo de ello han sido los mazahuas del Estado de México, mixtecos de Oaxaca y otomíes de Querétaro.

Las redes entre paisanos permitieron y facilitaron a los indígenas su inserción residencial y económica al llegar al área metropolitana. Migrar hacia Monterrey y su área metropolitana fue una opción ante las escasas oportunidades en otras ciudades en las que ya habían intentado vivir. Los casos más ilustrativos son los mazahuas y mixtecos, que antes de llegar al área metropolitana, habían vivido, por lapsos de uno o dos años, en otras ciudades. Los mazahuas recorrieron varias localidades del Estado de México, Distrito Federal y de los Estados Unidos, los mixtecos vivieron en Ciudad Juárez, Tijua$\mathrm{na}^{3}$ y Reynosa. Este continuo movimiento se debió, en gran medi$\mathrm{da}$, a la necesidad de establecerse en lugares que les facilitaran acomodarse económica y residencialmente, este hecho no se dio por motivos como la falta de vivienda. En cambio, en Monterrey, como resultado de varios procesos sociales de los que se hablará más adelante, el factor que permitió su residencia en esa ciudad fue encon-

${ }^{3}$ Cabe mencionar que en Tijuana reside el mayor número de migrantes mixtecos (Clark 2088). 
MAPA 1. Crecimiento urbano del AMM

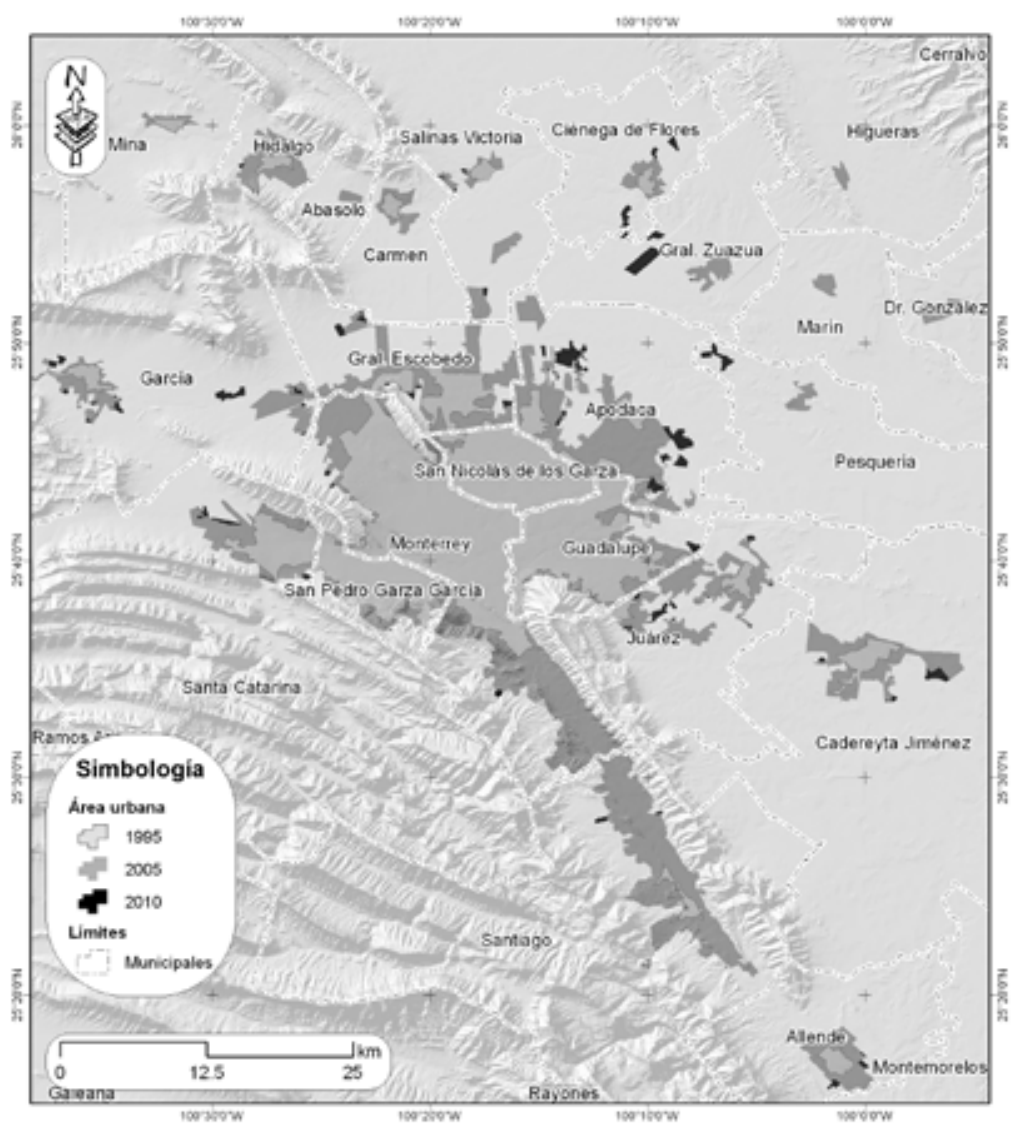

Fuente: Elaboración propia con datos del INEGI $(1995,2005,2010)$.

trar un espacio donde vivir, lo que atrajo más integrantes de dichas comunidades. ${ }^{4}$ Por ejemplo, entre el 2005 y 2006, los mazahuas del Estado de México recibieron créditos para acceder a casas de interés social, ubicadas en la periferia norte del área metropolitana en los límites del municipio de Monterrey (Durin y Pernet 2010), por

${ }^{4}$ Para mayor información sobre el proceso de migración y asentamiento de los mencionados grupos indígenas véase García 2010; Durin y Pernet 2010. 
Mapa 2. Proceso de incorporación de municipios que conforman el AMM

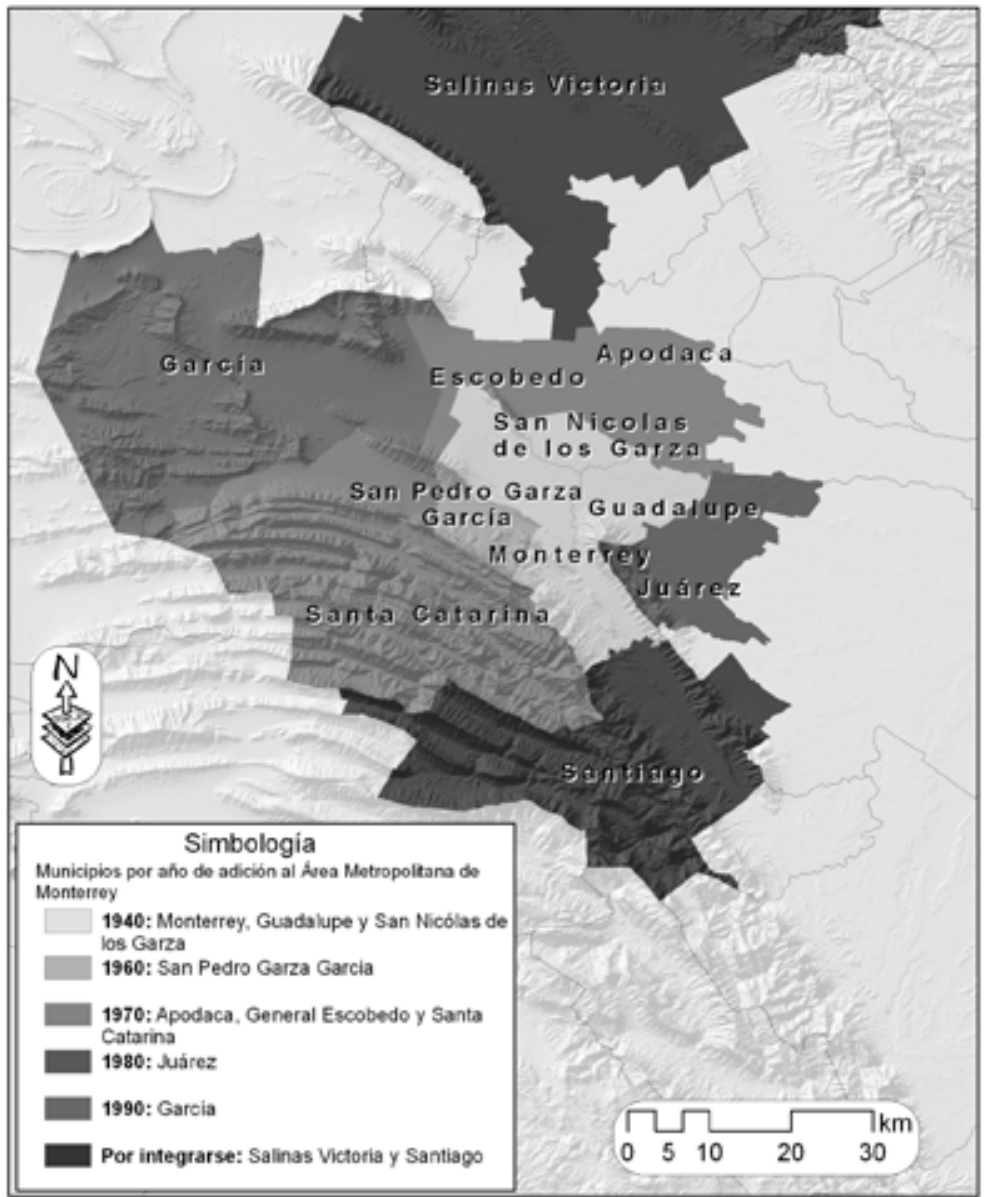

Fuente: Elaboración propia.

medio del instituto de la vivienda y de la intervención de la Comisión Nacional para el Desarrollo de los Pueblos Indígenas (CDI).

A pesar de la presencia y continuo aumento de la población indígena en el área metropolitana, la sociedad en general y las instituciones gubernamentales desconocían la presencia de indígenas. Sin 
embargo, la realidad social mostraba lo contrario, pues en las calles, en las avenidas, colonias, escuelas, comercios había indígenas donde sus necesidades y demandas no se hicieron esperar. El gobierno, a través de sus instituciones, ignoró los problemas de este sector, lo que ocasionó serias violaciones a sus derechos humanos. Ejemplo de ello son varios integrantes de la comunidad mazahua, quienes en varias ocasiones fueron hostigados por policías municipales y encarcelados (por vender en la vía pública) sin derecho a un traductor (Pernet 2009; Durin y Pernet 2010), o bien, la discriminación social de la que fueron víctimas niños, niñas y padres de familia indígenas en escuelas primarias públicas por no poder comunicarse con los maestros o por su fisonomía. Existen indígenas que han expresado haber sido objeto de discriminación o son ignorados por autoridades gubernamentales y la sociedad en general debido a su condición étnica.

A pesar de la situación de desventaja ante la sociedad mayoritaria, los grupos indígenas se organizaron para buscar soluciones a sus problemas, trabajando en conjunto, como actores sociales, en busca de la inclusión social; entendida como la oportunidad de acceso a la dinámica política, económica y social de un determinado lugar, donde los derechos de un grupo son respetados (De la Peña 1999; Fleury 1999). Pero no ha sido suficiente, para la mayoría de las instituciones gubernamentales y de la sociedad civil, los indígenas son vistos como migrantes, que en algún momento tienen que regresar a su lugar de origen, o bien, como un problema de pobreza, de marginalidad, de atraso, personas tercas que no quieren "adaptarse" al estilo de vida citadino. En este marco de desinformación, apatía o desinterés por parte del gobierno, han surgido personas de la sociedad civil interesadas en apoyar a los indígenas que viven en el área metropolitana. Esta esfera de actores o agentes sociales, integrada por instituciones académicas, grupos proindígenas y sociedad civil, se enfocó en hacer visibles a los grupos étnicos que viven en la metrópoli, fomentaron su inclusión social y promovieron la defensa en favor de los derechos indígenas, como el derecho a la participación política y legal, respeto por su organización social y costumbres, derecho a expresar sus símbolos culturales y lengua materna, entre otros. Ante este escenario, el objetivo de este artículo es describir el 
proceso por el cual los indígenas que radican en el AMM han sido visibles, resaltando la participación de la mencionada esfera de agentes sociales que han luchado por la inclusión social, económica y política de este sector de la población. Este conjunto de relaciones sociales entre actores ha sido elemento fundamental en la construcción de una espacialidad indígena en el АМм, la cual se define como un cúmulo de acciones entre actores que cambia o trastoca un determinado espacio geográfico y social (García 2010).

El documento presenta, en el primer apartado, las características generales de la migración indígena al AMM, señalando el incremento de la población indígena, los municipios donde se asientan y las actividades económicas que llevan a cabo. En el segundo apartado, se puntualizan los conceptos teóricos sobre el espacio y la identidad como ejes teóricos del análisis; este tema se relaciona con el tercer apartado, en el que se mencionan algunos trabajos escritos en torno a la presencia indígena en las ciudades, desde la antropología y la geografía, puntualizando algunas diferencias según la disciplina. En el cuarto apartado, se detallan las acciones y los hechos que forman parte del proceso por el cual se construye una espacialidad indígena, enfatizando las relaciones sociales tejidas por la participación de un grupo de agentes sociales. La relación y el impacto que han tenido estas agrupaciones sobre los indígenas y su visibilidad ante la sociedad mayoritaria se detallan en el quinto apartado. Por último se ofrecen las reflexiones finales.

La información que se ha utilizado en el presente artículo se desprende de la investigación de maestría (García 2010), la cual explica y analiza la inserción y organización socioespacial de los mixtecos, originarios de San Andrés Montańa Oaxaca, radicados en el municipio de Juárez al poniente del AMM. La información fue recabada en un periodo de tres años (2008-2010), se utilizaron herramientas metodológicas como la entrevista a profundidad y la observación participante de los indígenas en sus distintos espacios de confluencia como la colonia, viviendas, lugares de trabajo y esparcimiento. También se recogió información de primera mano con los integrantes de las comunidades mazahuas, otomíes y triquis; de las instituciones gubernamentales y sus representantes; de las organizaciones proindígenas y de la academia. 


\section{Presencia indígena en el Área metropolitana DE Monterrey}

Es importante retomar algunas cuestiones generales sobre la migración de indígenas al área metropolitana que facilitan la comprensión y análisis de la construcción socioespacial de este sector de la población. En el censo de 1970, realizado por el Instituto Nacional de Estadística y Geografía (INEGI), aparece por primera vez el registro de once hablantes de lengua indígena (HLI) en el estado de Nuevo León. En el censo de 1990 se registran 5,783 HLI, principalmente mujeres; esto se vincula con su ocupación laboral como empleadas domésticas de las zonas de clase media y alta (Durin 2008). La década de los noventa es significativa, pues marca la primera intervención del gobierno a favor de los indígenas en el campo de la educación, al crearse el Departamento de Educación Indígena, tema que se retomará más adelante. Entrado el nuevo milenio, el AMM alcanza la mayor tasa anual de crecimiento (12\%) de hablantes de población indígena (Durin, Moreno y Sheridan 2007). En ese momento, la participación de los grupos indígenas es activa, se organizan en asociaciones, se vinculan con las instituciones gubernamentales, universidades y sectores de la sociedad civil. Según el último censo, residen en el estado 40,137 HLI mayores de cinco años (INEGi 2010). Esto habla de un aumento continuo de la población indígena, del nacimiento de segundas generaciones $\mathrm{y}$, sobre todo, de que han hecho de la ciudad su residencia fija.

En 2010, los grupos etnolingüísticos más importantes son el grupo nahua $(21,723 \mathrm{HLI})$, huasteco $(5,974)$, otomí $(1,397)$ y zapoteco (950). Los indígenas residen dentro del área metropolitana, en especial, en los municipios conurbados de Monterrey, San Pedro Garza García y Guadalupe (mapa 3). Las residencias de los indígenas que viven congregados y dispersos ${ }^{5}$ suelen estar ubicadas en la

${ }^{5}$ Se identifican tres tipos de asentamientos, por un lado, el aislado, relacionado con los indígenas que tienen su residencia en el mismo lugar de trabajo, como sucede con las empleadas domésticas puertas adentro; el disperso, se refiere a las familias indígenas que, como su propio nombre lo indica, viven de manera dispersa en el área metropolitana; por último, los asentamientos congregados son aquellos en los que habitan al menos $20 \mathrm{fa}$ - 
periferia de los municipios, en las zonas calificadas como populares, carentes de servicios, y mal comunicadas (Durin 2008). Del tipo congregado se encuentran los mixtecos, localizados en la colonia Héctor Caballero (municipio de Juárez), los otomíes de las colonias Genaro Vázquez y Lomas Modelo (Monterrey), los mazahuas en el sector la Alianza y San Bernabé (Monterrey); y de un grupo de más de veinte familias nahuas originarias del estado de Veracruz, ubicadas en la colonia Arboledas de los Naranjos (Juárez).

El tipo de residencia (congregado) ha significado una ventaja sobre las demás, pues los grupos tienen mayor visibilidad ante las instituciones gubernamentales, al encontrarse ubicados en un mismo lugar donde su presencia no pasa inadvertida; además, permite la comunicación y organización entre sus miembros. Esto se traduce en la facilidad para acceder a programas sociales como Oportunidades, Programa de Alimentación (PAL), servicios de salud, acceso a la vivienda o mejoramiento de la misma. Entre este sector de la población indígena que vive congregada, la ocupación laboral ${ }^{6}$ de los HLI que interesa resaltar es la ejercida de manera informal en las calles y avenidas, como vendedores ambulantes de artesanías, dulces y bisutería.

Antes de los noventa se atendían poco las problemáticas que enfrentaban los indígenas en la ciudad, por ejemplo, la vivienda, servicios básicos y de salud, educación, legalidad, discriminación. El aumento constante de la población indígena, y la organización entre ellos, suscitó que las instituciones gubernamentales los visualizaran y los tomaran en cuenta. Fue un proceso que tomó más de diez años y las transformaciones también se observan en el espacio físico y no sólo en el social. Así sucedió en el primer cuadro de la ciudad de Monterrey, donde se ubica la central de autobuses, la Alameda y la Macroplaza.

La zona cercana a la central de autobuses se convirtió en un sitio para que las familias y las personas que llegaban por primera vez a la ciudad consiguieran un espacio para dormir, comer y establecer contactos con otros paisanos. Lugares de esparcimiento públicos

milias originarias de un mismo lugar, con un promedio de cinco miembros, en la misma área residencial (Durin 2008).

${ }^{6}$ Para mayor información sobre el tipo de ocupación y nichos laborales ocupados por la población indígena en el estado véase Durin, Moreno y Sheridan (2007) y Durin (2008). 
Mapa 3. Población hablante de lengua indígena por municipio del AMM

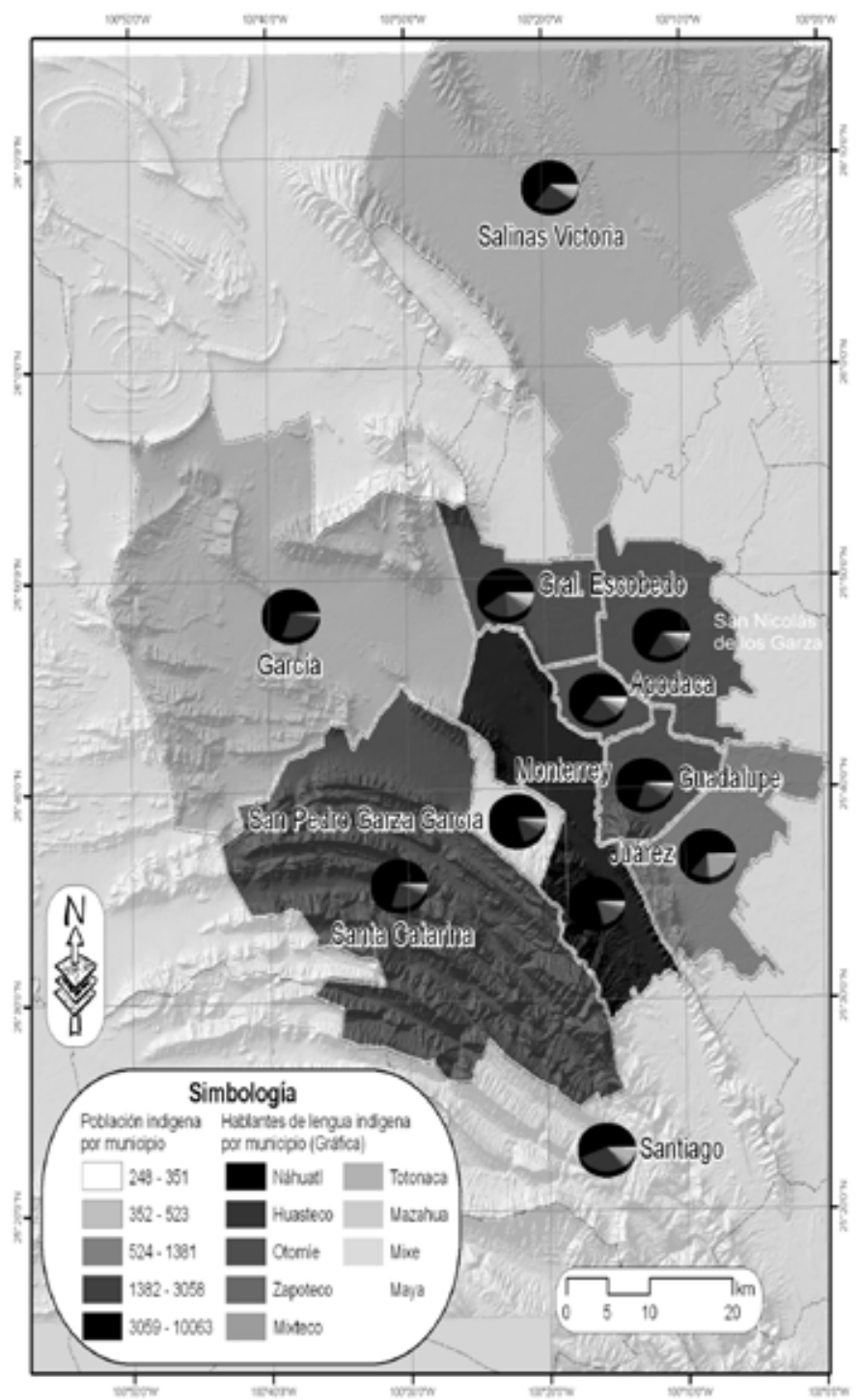

Fuente: Elaboración propia con datos del INEGI (2005). 
como la Macroplaza y la Alameda Mariano Escobedo, comenzaron a ser frecuentados y apropiados paulatinamente (Díaz 2008). Sin embargo, cabe resaltar que en la Alameda los cambios físicos son más evidentes, pues el área que la rodea se ha acondicionado con locales para satisfacer los gustos y las necesidades de sus visitantes: consultorios médicos, dentales, farmacias, centros nocturnos, hoteles, renta de cuartos, comercios de comida típica, puestos de boletos de autobuses, kioscos informativos, bancos para envío de dinero. Dicho espacio se convirtió en punto estratégico para las instituciones gubernamentales, asociaciones, organizaciones interesadas en trabajar o apoyar a este sector de la población (sobre todo a partir del 2000), como la apertura de un centro de ayuda para mujeres indígenas. Además, ha sido sede de varios festivales interculturales que dan a conocer las distintas culturas, tradiciones y lenguas habladas que existen en la ciudad. Como se ha descrito, la presencia de los grupos indígenas no pasa desapercibida en el espacio físico de la ciudad, pues ésta no contiene a la sociedad sino que está en íntima relación con ella. Esto se traduce en la apropiación y organización de la sociedad en el espacio urbano. La apropiación del espacio es un elemento clave en la construcción de la espacialidad indígena en el área metropolitana, ya que al apropiarse de un determinado lugar se puede observar la expresión cultural y simbólica de los grupos indígenas. Por ejemplo, es común que los domingos en la Alameda, los comerciantes de alimentos (originarios de San Luis) ofrezcan comida típica de la Huasteca Potosina como el famoso zacahuil, o bien, en los asentamientos congregados, como el de los mixtecos, la arquitectura de las casas se diferencia de los demás vecinos no indígenas, porque las familias han sembrado, en el patio trasero o delantero, un tipo de árbol conocido como mezquite, así como flores y hierbas medicinales. Asimismo, construyeron, en un pequeño lote, una capilla en honor a san Andrés Apóstol, su santo patrono. La capilla se localiza dentro de la colonia en la que viven en una de las calles donde se ubica un número importante de casas de mixtecos. El uso es exclusivo de la comunidad y es un espacio que está acondicionado con bancas para unas diez personas, atrio e imágenes de distintos santos. Un dato interesante es que la capilla se construyó a la par de 
la llegada de los mixtecos a esa colonia en el año de 1995 (García 2010). Esto habla de una apropiación del espacio y de una territorialización de los mixtecos en la colonia.

\section{ESPACIALIDAD E IDENTIDAD}

En los últimos años se ha hecho necesario incorporar teorías, visiones y metodologías de otras disciplinas para enriquecer el análisis o bien porque el mismo fenómeno lo demanda. La geografía es ejemplo de ello. A través de la trayectoria histórica de la disciplina, ésta ha incorporado modelos, teorías y herramientas metodológicas de otros campos de las ciencias sociales como la antropología y la sociología, en un esfuerzo para abrirse camino en las ciencias sociales (Chávez 2009, 12). Geógrafos como Barrows (1982), Frémont (2005) y Ortega (2007) propusieron la idea de que la geografía no sólo es el estudio de la tierra, lo físico, lo material, lo visible, sino en resaltar la importancia del hombre y su relación intrínseca con la naturaleza. Por ello, en la actualidad podemos hablar de una geografía interesada y preocupada en los problemas sociales sin olvidar, claro está, su objeto de estudio: el espacio, su principal aporte.

La geografía ha realizado esfuerzos para profundizar en los fenómenos sociales y culturales, en sus respectivos giros, con la finalidad de aportar novedosas visiones, conocimientos y análisis a las ciencias sociales. Además, poco a poco se ha introducido en temas que antes sólo eran abordados por ciertas disciplinas, como en este caso. Por ello, el presente trabajo trata un tema de tradición antropológica, como es la población indígena, pero intentando ofrecer una visión desde lo espacial.

Es común que en otras disciplinas de las ciencias sociales se lleguen a utilizar los conceptos de espacio, espacialidad o espacio social, lugar y territorio como similares. Sin embargo, para cada disciplina el significado suele ser diferente. El espacio, en una definición simple, es todo lo que rodea al hombre, es la distancia de un punto a otro o, bien, puede entenderse como todo lo que podemos observar. El espacio en la geografía, o mejor dicho el espacio geográfico, es aquel que está en intima relación con el individuo y los gru- 
pos humanos y con la organización que éstos le den. El espacio, es una de las dos dimensiones de la realidad que se estudia; la otra es el tiempo (Frémont 2005 en Fernández 2009, 110). El espacio es el objeto de estudio de la disciplina y éste tiene múltiples dimensiones tales como: lugar, áreas, regiones, paisajes, fronteras, sitios, migraciones, ambientes (Ibid.). Éstos constituyen lo objetivo y lo concreto del espacio o, como menciona Frémont (2005, en Fernández $2009,111)$, son los nombres propios. Así pues, el espacio al ser habitado, y por ende estar en relación directa con el hombre o los grupos humanos, se le imprime cierto carácter a través de símbolos (físicos e imaginarios) y rasgos de identidad. Tuan (1977) argumenta que el lugar se convierte en elemento central para el análisis de lo espacial. Cuando se crean vínculos entre un grupo y un espacio determinado, el espacio y se "convierte" en lugar; uno existe en otro, porque ese otro le da valor, le simboliza y crea territorio. El lugar es la relación entre algo y alguien (Bozzano 2009, 53). Entra entonces el elemento de identidad. Buttimer (1976) considera que la identidad personal y cultural del individuo está intimamente unida a la identidad del lugar.

La identidad es la afiliación con un territorio determinado y para que se llegue a dar tal afiliación es preciso simbolizar ese espacio (Novoa 2006). El territorio no es sinónimo de espacio o de lugar, sino que es el resultado de un proceso social que le da el carácter de territorio. Primero, existe un espacio que pasa a ser un lugar cuando los grupos le confieren valor e identidad, y como consecuencia de la afiliación, se le delimita creando fronteras y con ello un territorio cargado de intereses (políticos, económicos, sociales, religiosos, tradicionales). En el territorio confluye la organización socioespacial, en la que cada elemento tiene un lugar y una función que determina, entonces, lo que se delimita y el por qué se defiende. Desde una perspectiva social, Aceves (1997) considera al territorio como un lugar que ocupa un determinado grupo y cuyos miembros se comunican entre sí en términos de una misma tradición y organizados para la acción en común. Lo que también se identifica como territorialidad, en el sentido en que se manifiesta una relación al territorio, que va de lo colectivo a lo individual. En este sentido, el carácter de 
los grupos sociales está determinado por las relaciones que lo hacen posible. Las significaciones atribuidas al lugar poseen dimensiones simbólicas, emocionales, políticas, culturales y biológicas; las personas no poseen una sola concepción intelectual, imaginaria y simbólica del lugar sino que también se establecen las relaciones personales y sociales basadas en esquemas de interacción y afiliación, lo que genera la presencia y defensa de un territorio (Buttimer 1976).

El espacio social o espacialidad es un presupuesto, medio y producto para el proceso de producción y reproducción social. En este interactúan, no sólo los individuos y grupos, sino también poderes, posiciones e intereses que hacen a cada espacio social único en relación con otros, diferenciados por los valores, los hechos, la identidad y la geografía de cada sitio (Lindón 2006). El espacio socialmente construido es un objeto complejo y polifacético, la sociedad lo crea y lo recrea con una entidad física definida; es una representación social y un proyecto en el que los individuos, grupos sociales, instituciones y organizaciones operan. Para entender la espacialidad de los indígenas en el AMM, es importante concebirla como producto y reproductor social construido a partir de la relación con otras dimensiones espaciales, agentes externos, instituciones y sociedad civil. Los procesos de producción espacial existen, se hacen visibles, se organizan y articulan a partir de las condiciones existentes (Blanco 2007).

\section{LA POBLACIÓN INDÍGENA ANALIZADA DESDE LA ANTROPOLOGÍA Y LA GEOGRAFÍA}

La presencia y crecimiento de la población indígena en las ciudades, dentro y fuera del territorio nacional, ha sido un tema abordado por diversas disciplinas, pero hay que reconocer que la antropología tiene mayor tradición en el campo. Sin embargo se ha hecho necesario incorporar nuevas visiones que proporcionen análisis que complementen o enriquezcan la información aportada por las investigaciones antropológicas. La antropología ha incorporado a su análisis el factor espacio concibiéndolo como el escenario en el que se dan las relaciones sociales en un determinado grupo social y por ende trata 
de explicar cómo es que se efectúan (Fernández 2009, 108). Sin embargo, es necesario enfocar los fenómenos sociales desde una perspectiva espacial tomando en cuenta las cuestiones locales, regionales, territoriales (Ibid.). Por ello en los últimos años, la geografía se ha interesado por los estudios de población indígena. En las siguientes líneas se mencionan algunas de las investigaciones antropológicas y geográficas, que han abordado el tema de la migración indígena del campo a la ciudad y su presencia en las ciudades fuera y dentro del país. Cabe mencionar que existe una vasta literatura del tema en el campo de la primera disciplina por lo que sólo se hará mención de los trabajos escritos en recientes fechas.

La pionera en abordar el tema de migración indígena a una ciudad fue Arizpe (1975) al estudiar a los mazahuas originarios del Estado de México que se trasladaban a la ciudad de México en los setenta. La autora se centró en las causas que motivaron la movilidad hacia la urbe, entre éstas, destacó la crisis en el campo y las escasas oportunidades en sus lugares de origen como principales razones. El análisis de los motivos de expulsión fue la tendencia de los estudiosos del tema por más de una década, sin embargo, debido a los cambios en el contexto económico, político y social del país, se hizo necesario explicar el fenómeno de la migración desde otras aristas. Por ejemplo, Leal (2010) detalló que los trabajos comenzaron a tomar nuevos rumbos, dejando atrás el proceso y las causas que originaban la migración. En la misma línea, que la primera autora, Talavera (2006) demuestra que dichos estudios han pasado por dos fases: la primera, enmarcada en el análisis de la presencia de indígenas en las ciudades y de los motivos de movilidad; la segunda, enfocada en desarrollar la adaptación y la dinámicas en la ciudad. Es entonces que a partir de los noventa, una nueva generación de investigadores se enfocaron en la presencia de indígenas en las grandes ciudades del país como Ciudad Juárez, Chihuahua, Tijuana, Guadalajara y ciudad de México. La producción de trabajos realizados, a partir de entonces, se encierran en tres grandes grupos: 1) las implicaciones en términos étnicos de la migración, la importancia de las redes sociales, el reconocimiento de los derechos como pueblos indígenas; 2) los temas sobre segundas generaciones, enfatizando la re- 
producción de la etnicidad; 3) los estudios sobre género y el proceso de inserción social en la ciudad (Durin 2008).

Ejemplo de las anteriores afirmaciones es el trabajo de Martínez Casas y De la Peña (2004), quienes estudiaron la presencia del grupo otomí en Guadalajara. Los autores se centraron en analizar los mecanismos y las estrategias de inserción y resignificación cultural que dicho grupo étnico utilizó para adaptarse a la ciudad, profundizando sobre el concepto de multiculturalismo y ciudadanía étnica. Bajo la misma línea, Velasco (2008) trabajó en el proceso de la identidad de los migrantes indígenas originarios de la Mixteca, que residían en la ciudad fronteriza de Tijuana.

En otro nivel, se han escrito trabajos sobre las comunidades indígenas trasnacionales, donde autores como Barabas (2008), Lestage (2001, 2009), Besserer (2009), entre muchos otros, han dedicado sus investigaciones al fenómeno de las interacciones fronterizas, las identidades y la relación de los migrantes con su lugar de origen. De esta manera, hayamos una constante en las propuestas que nos presenta la nueva tendencia de estudios sobre indígenas en las ciudades, la cual reside en puntualizar el proceso de cambio o resignificación de la identidad y los mecanismos de negociación ante un nuevo espacio.

La geografía en México se está abriendo camino en el tema de la movilidad y presencia de indígenas en las ciudades. Ha sido un proceso paulatino y significativo en cuanto aportes teóricos y metodológicos. Se ha pasado de información meramente cuantitativa a hacer análisis cualitativos, combinando herramientas de otras disciplinas pero aportando su particular punto de vista basado en el análisis del espacio. La geografía también ha pasado por fases, en cuanto al tema que aquí compete, después de centrarse sólo en los efectos de la migración en general (por ejemplo, impacto en la economía y en la demografía) ha comenzado a adentrarse en el terreno subjetivo (imaginarios, mapas mentales, espacios vividos) del fenómeno.

Se ha identificado que los estudios realizados en torno al tema de la migración indígena (desde la geografía), se pueden distinguir en tres fases: 1) temas que abordaron los flujos migratorios de la población en general, enmarcados en el análisis cuantitativo; 2) trabajos sobre migración internacional y el impacto demográfico en los luga- 
res de migración y de inmigración; 3) la nueva generación de investigaciones, que además de abordar la migración se centran en el sector de la población indígena (García 2010). Ejemplo del primer punto es la rama de la geografía de la población que ha realizado su aporte con base en los métodos cuantitativos: el número de migrantes, las ciudades a las que llegan, la dinámica económica, etcétera, privilegiando los resultados numéricos para dar explicación a la movilidad por parte de los individuos (Mendoza 2006, 163) Ortiz (2005) realiza un exhaustivo y detallado análisis cuantitativo de la ubicación territorial de los HLI en el territorio nacional. Por otro lado, el trabajo de Granados (2005) explica los motivos por los cuales los flujos migratorios de la población indígena cambian y han empezado a tener nuevas ciudades de destino.

La segunda fase se caracteriza por los trabajos de geógrafos dedicados a estudiar los flujos migratorios de México hacia Estados Unidos, puntualizando el transnacionalismo (Faret 2001). A diferencia de otros, el autor deja abierta una puerta para los geógrafos interesados en el tema, pues concluye que la movilidad trae consigo nuevas relaciones con el medio, lo que implica una reconfiguración de la identidad del individuo. En este sentido, Mendoza (2006) sugiere que la geografía tiene que iniciar a trabajar en conjunto con métodos, teorías y disciplinas que aporten de manera sustancial un análisis multidisciplinario. La rama de la geografía rural también aportó. En trabajos como el de Paniagua (2006) se hizo hincapié en las causas que motivaron a los indígenas campesinos a migrar a ciudades dentro y fuera del país, entre éstas, la crisis en el campo y los conflictos agrarios. Sin embargo, no se profundizó más allá de la explicación, pero a diferencia de otros trabajo, éstos comienzan a diferenciar a la población que llegaba a la ciudad procedente del campo.

La última fase que se plantea la componen los estudios enmarcados por la geografía social y la cultural. Se basan en tener como sujetos de estudio a la población indígena que se inserta en ciudades del país, como Hiernaux (2000) que expone la compleja relación entre la ciudad y la etnicidad de los indígenas que llegan a vivir a la periferia. Por su parte, Urbalejo (2009) versa su investiga- 
ción sobre el proceso por el cual una comunidad mixteca, originaria de Guerrero, construye un espacio vivido en la ciudad de Tijuana, donde los integrantes del grupo, en su cotidianidad, imprimen a los lugares símbolos propios de su identidad, construyendo a su vez territorios. Retoma la importancia de la ciudad, con su historia y temporalidad, como factor que influye en los actores en la conformación de sus espacios de vida.

Por último, se mencionan algunos trabajos de corte antropológico que conjugan el análisis del espacio y de la etnicidad de grupos indígenas en las ciudades. Camus (1999) muestra la diversidad de vinculaciones posibles entre los conceptos de espacio y etnicidad en un estudio realizado en la Ciudad de Guatemala. Estudia a distintos sectores de la población indígena (comerciantes, mano de obra disponible) y la relación con el medio urbano. La presencia de indígenas en Ciudad Capital, según la autora, forma parte de un proceso de territorialización múltiple de espacios de composición étnica mixta (indígenas y ladinos). El trabajo describe, entre otras cosas, cómo los espacios (mercados, barrios y colonias) se apropian y se simbolizan por los actores implicados, además se aprecia que la espacialidad está vinculada con la historia y las dinámicas en las que radican los grupos indígenas en Guatemala.

Sobre la misma línea, Díaz (2008) centra el análisis en la apropiación de espacios públicos como el caso de la Alameda Mariano Escobedo en Monterrey. Describe cómo, a través del tiempo, los visitantes de dicho espacio han cambiado. Dejó de ser un lugar propio de la clase acomodada, que vivía en las cercanías, para ser apropiado por los migrantes que hallaron en él, un sitio donde tejer redes sociales para conseguir vivienda, trabajo y además para reunirse con familiares o amigos.

Oehmichen (2011) ilustra el fenómeno de la presencia de grupos étnicos en las ciudades, sin embargo, a diferencia de los trabajos mencionados, puntualiza la producción de espacios de segregación. La autora analiza la segregación de los indígenas y su reflejo en los espacios físicos de la ciudad de México. Algunos muestran la jerarquía social que hace perfectibles los valores y símbolos de quienes los habitan o frecuentan. Es el caso de ciertos lugares del centro 
histórico de la ciudad de México, como la Merced, la central de abastos, el Zócalo y su área circundante, que funcionan como zona habitacional y laboral de familias indígenas de bajos recursos que enfrentan riesgos por vivir en edificios en mal estado, delincuencia, pobreza, falta de acceso a servicios básicos y de educación, además de amenazas constantes de desalojo. Por otro lado, la autora se refiere a los espacios "intersticiales" que define como aquellas residencias de grupos indígenas que se localizan en zonas de clase media compartiendo el espacio con no indígenas, quienes asocian los lugares donde viven los indígenas como "zonas peligrosas". Este tipo de investigaciones muestra que la presencia de grupos indígenas en las ciudades no pasa desapercibida para la sociedad anfitriona. Los trabajos que se han mencionado muestran que la relación se refleja en la morfología de las ciudades (ocupación de colonias y barrios en la periferia de la ciudad), espacios públicos apropiados, segregados por la condición de ser indígenas hasta espacios que recrean física y socialmente la dinámica del lugar de origen y permiten o no la solidaridad comunal, las redes sociales y familiares.

\section{LA ESPACIALIDAD DE LOS INDÍGENAS EN EL AMM:}

PROCESO DE CAMBIO Y RELACIONES SOCIALES

La espacialidad es un proceso de cambios y trasformaciones en un determinado espacio geográfico (en este caso el AMM) en el cual hay intercambio de información, conocimientos y donde se establecen relaciones con los actores implicados. Para hablar de una espacialidad es preciso mencionar cuáles son dichos cambios, quiénes han intervenido y cómo se vinculan los hechos y las acciones. En este apartado se detalla a una esfera de actores sociales que han participado directamente en el proceso para la construcción de una espacialidad indígena en el AMM, implicados en hacer visibles a este sector de la población, sus derechos, sus diferencias, necesidades, entre otras cosas. Se afirma que las acciones, hechos e iniciativas vinculadas a indígenas son elementos a través de los cuales se ha ido forjando la espacialidad. Dichos factores se han dividido en tres tipos: los de carácter institucional o gubernamental; los realizados 
por un sector de la sociedad civil; por último, los que competen a los grupos indígenas. Es importante señalar que cada acontecimiento está íntimamente vinculado al proceso de inserción social, residencial, económico y político de los indígenas en la ciudad. Así como también al tipo de demandas que cada grupo ha presentado a través de los años.

\section{Desde el gobierno federal, estatal y municipal}

Se mencionó en la introducción que la década de los noventa fue un momento en el cual el número de HLI aumentó considerablemente y fue cuando un sector de la población indígena llamó la atención de las instituciones gubernamentales por primera vez. En algunas escuelas primarias públicas se encontraron nińos y niñas de origen indígena y tras negociaciones con la Dirección General de Educación Indígena, la Secretaría de Educación en el estado se iniciaron acciones ${ }^{7}$ para atender la situación.

En 1998, la Secretaría de Educación en Nuevo León toma en cuenta a los alumnos indígenas que asistían a escuelas primarias ubicadas en las colonias donde había asentamientos indígenas (Durin 2008). Para tal efecto, en 1999, se creó el Departamento de Educación Indígena (DEI) con el objetivo impartir una educación intercultural a través de clases que se imparten en alguna lengua indígena (náhualt, mixteco, otomí). Entrado el nuevo milenio se aprobó una modificación a la Ley de Educación para el Estado de Nuevo León, promovida por el DEI en la que se menciona que es obligación la atención de grupos indígenas (Durin 2007, 76). En el 2002, el DEI, inicia de manera oficial la impartición de clases de lenguas indígenas en escuelas primarias localizadas, principalmente, en las colonias caracterizadas por la residencia congregada ${ }^{8}$ de familias indígenas (Ibid.). Ésta, marcaría el inicio de la atención a los indígenas en distintos ámbitos de la vida social.

${ }^{7}$ Para mayor información sobre el tema, véase Durin (2007).

${ }^{8}$ En el municipio de Juárez, en la colonia Arboledas de los Naranjos (nahuas) y en la Héctor Caballero (mixtecos); en Monterrey, en la colonia Ampliación Lomas Modelo (otomíes). 
En el 2003, como consecuencia de las crecientes demandas de los grupos indígenas, el entonces Consejo de Desarrollo Social ${ }^{9}$ intervino a través del departamento de Marginación Rural y Urbana para conocer las necesidades de la población indígena y trabajar en conjunto. Se focalizaron en los asentamientos de tipo congregado por la facilidad que representaba el que residieran en una misma colonia. Esto es criticable pues la mayoría de las acciones realizadas por el gobierno poco impactan en otras familias indígenas, precisamente, por vivir de manera dispersa o aislada. Tres años después de este acercamiento, se propuso crear espacios interculturales dentro de las colonias con mayor presencia de familias indígenas. Su función sería fomentar la convivencia entre mestizos e indígenas y el desarrollo de los colonos a través de clases y talleres. Así, en el 2006, se inaugura en la colonia Héctor Caballero con población mixteca y en la colonia Arboledas de los Naranjos con población nahua, los primeros Centros Comunitarios Interculturales (ambos en el municipio de Juárez). El primero permaneció sin ser visitado por la comunidad mixteca, pues no lo asumieron como propio y no tenían la intención de compartirlo con los demás vecinos (no indígenas). El segundo fue aceptado por los nahuas quienes mantuvieron su distancia con los mestizos, pero asistían a los talleres e inclusive, algunas señoras nahuas, ofrecieron clases de bordado para todo público. A seis años de su apertura estos espacios han sido sede de acontecimientos importantes para las comunidades, por ejemplo, la constitución de organizaciones indígenas, encuentros con otros grupos étnicos radicados en el AMM, la visita de personalidades del medio artístico como la del pintor Francisco Toledo, ${ }^{10}$ oportunidades de estudios, entre otros. Para las instancias de gobierno estos es-

${ }^{9}$ Ahora Secretaría de Desarrollo Social.

${ }^{10}$ La visita del artista plástico Francisco Toledo se dio en el marco del Forum Universal de las Culturas 2007, respondiendo a la invitación del gobernador Natividad Gonzáles Paras para realizar esculturas en diversos puntos de la ciudad. Toledo tuvo la oportunidad de conocer a la comunidad mixteca asentada en la colonia Héctor Caballero, que aprovechó la oportunidad para expresarle el problema del fraude e ilegalidad de los terrenos que habían adquirido años atrás. El artista les brindó apoyo económico para solucionar el problema, donó parte del pago que le haría el gobierno estatal. Dicha acción comprometió al gobernador a donar la misma cantidad. 
pacios interculturales cobran relevancia en el discurso o cuando se quiere mostrar la diversidad cultural que existe en la ciudad y, sobre todo, el trabajo que ejerce para apoyarlos (García 2010).

Para sostener a los Centros Comunitarios Interculturales es necesario el apoyo tripartita del gobierno estatal, municipal y federal, este último es representado por la Comisión Nacional para el Desarrollo de los Pueblos Indígenas (CDI). Desde principios del dos mil, la CDI supo de indígenas radicados en el estado a través de las demandas del grupo mazahua, que realizó visitas a la sede nacional en el Distrito Federal, después se unieron los mixtecos (Durin y Pernet 2010). Los grupos exigían que se les apoyara para resolver varias situaciones que les aquejaban y eran insostenibles. Los mixtecos expusieron el fraude por la compra de terrenos (en la colonia Héctor Caballero), problema que no habían podido solucionar y estaba ocasionando divisiones dentro de la propia comunidad. Los mazahuas describían, en el oficio que enviaron, los enfrentamientos violentos con la policía municipal de Monterrey por vender en la vía pública. Además de los actos de discriminación y hostigamiento, por último, pidieron que les facilitaran el acceso para tener vivienda propia (Ibid.).

Ante este contexto, la CDI intervino de distintas maneras para tratar de solucionar las vicisitudes expuestas. Conoció a otros grupos étnicos que también radicaban en la urbe regia. De tal manera, en el 2004, se instala de manera oficial una dependencia en el estado para atender las distintas problemáticas y necesidades de este sector de la población regia. Se puede atribuir su llegada, entre otras cosas, a las constantes intervenciones de los mazahuas y mixtecos quienes, hasta la fecha, no han dejado de estar presentes. Éstos fueron, y siguen siendo, de los grupos étnicos más activos y beneficiados por la CDI, que les recomendó integrarse en asociaciones civiles para concursar en proyectos nacionales para el apoyo de los indígenas. La comisión también es un puente entre los HLI y las instituciones, el caso de los mazahuas ilustra el beneficio de dicha relación, pues el Instituto Estatal de la Vivienda les facilitó créditos para el acceso a la vivienda (Durin y Pernet 2010).

A través de los festejos del Día Internacional de la Lengua Materna (21 de febrero), el día de los Pueblos Indígenas (9 de agosto) y la 
tradición de los altares de muertos (20 de noviembre), que se instalan anualmente en el Parque Fundidora, se reconoce la diversidad cultural en el estado. Estos eventos permiten la participación conjunta de las comunidades indígenas con las instituciones. El Instituto Nacional de Lenguas Indígenas (INALI) eligió al AMM, como sede del taller anual en el 2007. El DEI también inició jornadas de educación multicultural que pretendían sensibilizar e informar a maestros y directores de escuelas primarias sobre la presencia de indígenas en las escuelas y sus necesidades.

Cabe hacer mención que la relación entre los grupos indígenas e instituciones de gobierno no siempre ha sido positiva. Han pasado etapas de tensión y distanciamiento por parte de las comunidades que desaprueban las decisiones de los representantes de las instituciones de gobierno, sobre todo, cuando no se les beneficia directamente. Es cuestionable la percepción del gobierno ante la población indígena, lo que se refleja en la creación de programas de desarrollo; el indígena es visto como un objeto que experimenta un problema el cual es necesario resolver, y no como un sujeto con problemas que son el resultado de procesos históricos y de su posición dentro de la sociedad dominante (Besserer 2009).

\section{Grupos proindigenas}

En este trabajo se define a grupos proindígenas como aquellos formados por iniciativa de personas no indígenas interesadas en conocer, apoyar y trabajar directa o indirectamente con los HLI que radican en el área metropolitana. En su mayoría, lo integran jóvenes que iniciaron su contacto a través de los eventos organizados por la Secretaría de Desarrollo Social y la cDI. Surgieron a partir del año 2007 en adelante. En esta década se da la mayor tasa de crecimiento anual (12\%) en comparación con otros estados de la república (Durin, Moreno y Sheridan 2007), además, se llevaron a cabo varios eventos (gubernamentales, académicos, independientes) que dieron a conocer la diversidad cultural de las comunidades a la sociedad regiomontana a través de pláticas, talleres, conferencias, trabajos de investigación y medios de comunicación. Se suma una 
mayor producción e interés por estudiar el fenómeno de la migración y presencia de indígenas en el noreste del país, abarcando distintas problemáticas, por parte de instituciones académicas como la Universidad Autónoma de Nuevo León (UANL), Centro de Investigaciones y Estudios Superiores en Antropología Social (Ciesas), y el Instituto Nacional de Antropología e História (INAH), estas dos últimas con sede en el estado.

En 2007, la ciudad de Monterrey tiene proyección internacional como anfitriona del evento Forum Universal de Las Culturas. Paradójicamente, apuntaba a llamarse Ciudad del Conocimiento, ofreciendo un paisaje urbano-industrial con colosales diseńos y construcciones como la Macroplaza o el recién inaugurado Paseo Santa Lucía, lugares que se "limpiaron" de vendedores ambulantes, entre éstos los indígenas, para dar su mejor cara a los visitantes. A la par, y algo contradictorio, se llevaban a cabo conferencias y pláticas sobre la multiculturalidad e interculturalidad del estado resaltando a las comunidades indígenas como portadoras de cultura.

En este contexto alumnos y exalumnos de la Universidad de Monterrey (UdeM) y el Instituto Tecnológico de Estudios Superiores de Monterrey, campus Monterrey (ITESM) se interesan en conocer la historia de los pueblos indígenas para apoyarlos de distintas maneras. La UdeM inició conferencias de temas relacionados con los derechos y educación indígena. Por su parte, alumnos del ITESM forman la Asociación Estudiantil por los Pueblos Indígenas (AEPI), quienes organizan encuentros, reuniones y talleres para difundir la situación de las comunidades radicadas en la ciudad. Esta última ha colaborado con los mixtecos, mazahuas y un pequeño número de indígenas triquis y huicholes, así como también con el grupo Nuevo León Árbol de Todas Raíces que se formalizó en el año 2008. Este grupo ha sido controvertido desde su formación. En un principio sus integrantes habían formado parte de las filas de trabajadores del Consejo de Desarrollo Social, donde tuvieron la oportunidad de trabajar directamente con las comunidades indígenas en los Centros Comunitarios Interculturales y otros puntos. Se relacionaron con mixtecos, mazahuas, nahuas (de la colonia Arboledas de los Naranjos) y otomíes, principalmente. Al dejar de colaborar con el Consejo de Desa- 
rrollo Social, los extrabajadores interesados en seguir apoyando a los indígenas crean el grupo con el objetivo de integrar a todos los grupos étnicos residentes en la metrópoli y con ello visibilizarlos enfatizando su inclusión social para la creación de una sociedad plural y con igualdad de derechos. El grupo representó para las instituciones gubernamentales un elemento "incomodo", pues hasta ese momento nadie más intervenía a favor de los indígenas. El nuevo grupo propuso otro tipo de visión; trabajar en los problemas de la población indígena y su inserción social en la ciudad. La particularidad de éste, fue la manera en que reunió a los representantes de las comunidades para colaborar en proyectos colectivos, laborando de manera conjunta para que todos fueran beneficiados. Además, uno de sus objetivos era que los integrantes de las comunidades indígenas se conocieran entre sí para lograr tejer lazos de solidaridad entre ellos, este hecho motivó a algunos indígenas a exigir derechos y soluciones a sus demandas, por ejemplo, en conseguir recursos para la educación de sus hijos, permisos para vender en espacios públicos, entre otros.

Por otro lado, así como la relación entre el gobierno y los indígenas se vio afectada por desacuerdos (por beneficios o apoyos que unos grupos recibían y otros no), también sucedió con el grupo Nuevo León Árbol de Todas Raíces. Para algunos representantes de organizaciones indígenas, la experiencia de formar o colaborar con el grupo les sirvió de plataforma para conocer el contexto políticosocial, relacionarse con actores políticos, saber cómo hacer oficios y a quién dirigirlos con la finalidad de ser ellos, los propios portavoces y representantes de las peticiones ante las instancias gubernamentales y sacar mejor provecho.

En la actualidad en las oficinas del grupo imparten clases de náhuatl, ofrecen talleres y se han sumado otras iniciativas para apoyar a la población indígena, como el caso de Enlace Potosino. Este grupo de jóvenes originarios de varias localidades de San Luis Potosí (indígenas y no indígenas) se reunieron en el 2009 para poner en marcha un proyecto con la finalidad de crear una sociedad más responsable con su realidad social. Funge como enlace, tal como su nombre lo dice, entre el AmM y San Luis Potosí. Buscan apoyar a sus paisanos en asuntos relacionados con papelería personal (actas de 
nacimiento), trabajan para crear lazos institucionales entre ambos gobiernos. Su más reciente proyecto es "Certeza Jurídica para los Pueblos Indígenas Potosinos”, que tiene por objetivo facilitar a la población oriunda del mencionado estado el acceso al registro civil, pues es frecuente que los migrantes carezcan de actas de nacimiento (por extravío o sin actualización), el grupo hace un enlace con las oficinas gubernamentales para facilitar el trámite y que el solicitante no se tenga que trasladar hasta su lugar de origen. Procuran colocar carteles informativos en la zona de la Alameda para abarcar más población y darse a conocer.

Zihuakali es una iniciativa que se desprende de la asociación $\mathrm{Zi}$ huame Mochilla, ${ }^{11}$ la cual en sus inicios trabajó con las mujeres nahuas de la colonia Arboledas de los Naranjos con programas como la regularización de actas, apoyo para las familias en crisis, becas escolares, capacitación para el desarrollo de habilidades de liderazgo para jóvenes, entre otros. ${ }^{12}$ Obtuvo en fechas recientes apoyo federal por parte de la CDI para poner en marcha la mencionada casa de la mujer, éste es un programa que la CDI ofrece normalmente en zonas rurales.

Cabe destacar que los grupos proindígenas como Nuevo León Árbol de Todas Raíces, Zihuame Mochilla y Enlace Potosino junto con asociaciones indígenas, sociedad civil y gobierno han comenzado a trabajar conjuntamente en proyectos artísticos y culturales donde se busca dar a conocer las diferentes etnias y culturas indígenas que viven en el AMM. Ejemplo de ello fue el evento realizado en el 2010, Reflexiones de los Pueblos Indígenas en Nuevo León celebrado con la colaboración del Congreso del Estado, se invitó a la sociedad nuevoleonesa a participar en el encuentro de grupos indígenas, organismos de gobierno, sociedad civil organizada e instituciones académicas. Ahí se trató la problemática de los indígenas en la ciudad, se expusieron propuestas de políticas publicas y leyes que tomen en cuenta a los HLI que viven en el estado y su área metropolitana y con ello facilitar la inclusión, respetar sus derechos, usos y costumbres de las muy particulares comunidades étnicas.

${ }^{11}$ Está escrito en lengua náhuatl, en español se traduce como: mujeres con esperanza.

${ }^{12}$ Información obtenida en Revista Violeta, núm. 20, diciembre 2008, 2-4. 
El surgimiento y conformación de grupos proindígenas es resultado, no sólo del interés que causó la presencia de HLI, sino también, como una alternativa de apoyo a la que era complicado acceder. $\mathrm{Si}$ bien, la mayoría focalizó la atención en las comunidades con mayor visibilidad (mazahuas, otomíes, mixtecos y nahuas), poco a poco han extendido sus redes de apoyo a otros indígenas que están dispersos por la metrópoli.

\section{Asociaciones indigenas}

La formación de asociaciones indígenas es una respuesta ante la incipiente y lenta participación de las instituciones gubernamentales hacia ellos. Este tipo de organizaciones ha tratado de ejercer mayor visibilidad y presión para resolver problemas y necesidades (García 2010). Es una herramienta utilizada por los grupos para tener acceso a recursos tales como vivienda, servicios de salud, becas escolares, apoyos en especie y económicos. La formalización significó la participación activa de los indígenas como actores sociales en la urbe regia.

A manera de ilustración, los mazahuas, oriundos de Temascalcingo, Estado de México, son los primeros en organizarse. En el 2004, forman la Asociación Mazahua del Norte de México, Julia de Jesús Fernández, A. C., con la finalidad de hacerle frente a los maltratos y discriminación que recibían por parte de la autoridad, quienes en sucesivas ocasiones abusaban de su poder al confiscarles, de manera injustificada, la mercancía que vendían en las avenidas y calles de la ciudad.

En 2007, dos jóvenes indígenas estudiantes de la carrera de Derecho ${ }^{13}$ integran la asociación Procuración de Justicia Étnica, con el objetivo de apoyar a los indígenas en problemas jurídicos. A su vez, esto evidenció la inexistencia de programas e instancias del gobierno que coadyuvaran con este sector de la población.

La comunidad mixteca siguió los pasos de los mazahuas y formaron dos asociaciones para contar con representatividad y acceder a los recursos de gobierno. La primera fue Unida Mixteca A. C. creada

${ }^{13}$ Gabriel de origen nahua y Federico, mixteco. 
en 2007. La segunda Por Nuestra Identidad Mixteca A. C. (2008). Estas asociaciones han tenido un papel importante en la configuración de la espacialidad de los indígenas, pues se han mantenido presentes mediante la relación constante con actores políticos e institucionales, con el fin de ejercer presión para obtener apoyos para su comunidad. Una de las últimas conformaciones es la de los otomíes, que al igual que los mazahuas y mixtecos viven de manera congregada en colonias de la periferia de la AMM, formaron a finales del 2009 Hñahñu Dintuge Metige. Otomíes Defendiendo lo Nuestro A. C., con el mismo objetivo de las demás asociaciones, tratar de obtener recursos y ser visibles para las instituciones.

Por último, en el 2010, se forma otra asociación de un grupo mazahua originario del Estado de México, Mazahuas de Arboledas de San Bernabé A. C., haciendo referencia a la colonia en la que habitan. ${ }^{14}$ Ésta es un reflejo del proceso de inserción de los indígenas, pero además es un elemento clave en la configuración de la espacialidad, pues se enfocan en formar proyectos de gran envergadura laboral al tratar de incursionar en el ciberespacio con una página virtual que dé a conocer los servicios laborales que ofrece dicho grupo.

Las asociaciones son un elemento clave para la construcción de la espacialidad de los indígenas en la ciudad. Resalta su participación como actores sociales que interactúan a través de acciones, iniciativas y propuestas con la sociedad mayoritaria y en especial con las instancias gubernamentales. Esto es la capacidad de agencia del grupo por resolver su situación de manera independiente, organizado como grupo étnico.

INTERACCIÓN ENTRE GRUPOS PROINDÍGENAS, INSTITUCIONES GUBERNAMENTALES Y ASOCIACIONES INDÍGENAS

Los grupos proindígenas, las asociaciones civiles de indígenas y las instituciones de gobierno tienen un fin en común: apoyar a las comunidades indígenas residentes en el área metropolitana. Cada uno

${ }^{14}$ Colonia San Bernabé, sector La Alianza ubicado en los límites del municipio de Monterrey y García. 
con distintas herramientas y en diferentes campos (jurídico, salud, educativo, laboral, vivienda, social). Pero esta esfera de actores carece de comunicación, interacción entre ellos y de organización para trabajar en objetivos comunes con los grupos indígenas. Por ejemplo, hace falta que conformen una red, para tener mayor representatividad y ejercer cierta presión para agilizar las iniciativa de una ley indígena; canalizar a personas, extender y abarcar el apoyo a más indígenas que viven en zonas marginadas del área metropolitana, mal comunicadas, pero sobre todo, desinformadas de la existencia de lugares que les apoyan.

Como en toda relación, han existido diferencias, preferencias, tratos asistencialistas y verticales. Si bien, la CDI y el entonces Consejo de Desarrollo Social (ahora Secretaría de Desarrollo Social) fueron las primera instancias en acercarse para resolver las demandas primarias de ciertos grupos (mixtecos, nahuas y otomíes), de cierta manera al carecer de experiencia, voluntad y una evidente desinformación sobre los pueblos indígenas en México, trataron, y siguen tratando, a los indígenas de manera asistencialista. Esto es, satisfaciendo sus necesidades inmediatas sin una intervención directa en campo, sin conocer sus usos, costumbres, necesidades. Además, se han centrado en los grupos congregados que viven en una misma área residencial como los mazahuas, mixtecos, otomíes y algunos nahuas, dejando de lado a indígenas que viven de manera dispersa (como los tenek) en el área metropolitana. Esto ha fomentado la visibilidad de algunos grupos y la invisibilidad de otros.

Además, la ubicación geográfica de los centros comunitarios, de las oficinas de la Secretaría de Desarrollo Social, de la CDI y de cada una de los grupos proindígenas es una limitante para que otros indígenas tengan conocimiento de su existencia. Gran parte de los 40,000 indígenas que radican dentro del área metropolitana tienen su residencia en las zonas periféricas de los municipios por lo que sus espacios frecuentados no suelen coincidir con los lugares de apoyo. Los dos centros comunitarios interculturales, mencionados en párrafos anteriores, se localizan al este del Амм (en el municipio de Juárez) a una hora de camino (en transporte público) del centro de la ciudad de Monterrey. La Secretaría de Desarrollo Social que com- 
parte edificio con la CDI, se localiza al noreste del AMM, en el municipio de Guadalupe a treinta minutos del centro de Monterrey. Por su relativa cercanía con el centro de la principal ciudad del área metropolitana, el acceso en transporte público (camiones urbanos o metro) facilita a los usuarios llegar a las oficinas. Pero el factor distancia entra en juego para los indígenas que viven o trabajan fuera de esta área, por ejemplo, en los municipios de Escobedo y Apodaca, pues el tiempo que invierten en llegar puede ser hasta de dos horas, suponiendo que saben de la existencia de dichas instituciones. Por su parte, los grupos proindígenas, como Zihuame y Nuevo León Árbol de Todas Raíces han procurado tener sus oficinas en el primer cuadro del centro de la ciudad de Monterrey.

Si bien es cierto que para atender a toda la población indígena radicada en la urbe se necesitan recursos humanos y económicos, existen herramientas como las redes sociales, entendidas como un conjunto de relaciones entre individuos en los que interviene el intercambio de información, bienes o personas (Forni et al., 2004), para extender la información hacia otros puntos de la ciudad para que su alcance e impacto sea mayor. Los grupos proindígenas, las instituciones gubernamentales y todos los actores implicados, sin duda han influido considerablemente para hacer visible la presencia de indígenas en la ciudad. Pero como se ha mencionado sólo ciertas comunidades son las que han sido beneficiadas, en gran medida esto se explica por su tipo de residencia (congregado) que permite la constante relación y comunicación entre los miembros de una determinada comunidad (como los mixtecos, otomíes, mazahuas y algunos nahuas) para organizarse y hacerle frente a sus problemas. Asimismo, esto les facilita a los agentes externos focalizar y trabajar directamente con estos grupos, pues no tienen que buscarlos o identificarlos en la urbe regía, sino que ya están ubicados en un determinado lugar.

Cabe mencionar que la mayoría de las asociaciones indígenas se han formado por asesoramiento con los grupos proindígenas, quienes los han guiado para organizarse y acceder a los recursos de gobierno, como son los proyectos productivos y de bienestar social. El grupo Nuevo León Árbol de Todas Raíces ha estado implicado en estos hechos sobre todo con los mixtecos. En cambio, los mazahuas 
trabajan de manera conjunta con la cDi y la Secretaría de Desarrollo Social en proyectos productivos tales como la venta de flores a través de internet. Para ello se han instruido decenas de personas en talleres de computación y asesoramiento para manejar esta herramienta tecnológica. Es importante señalar que la relación laboral entre indígenas e instituciones gubernamentales y no gubernamentales depende de las necesidades que los primeros tengan (vivienda, educación, cuestiones legales, salud); ésta es temporal y cíclica, no siempre es estrecha ya que mucho depende del tipo de apoyo y condiciones que pidan las segundas. Los indígenas aprendieron a negociar con su identidad, reconociendo en qué espacios se puede ser miembro de algún grupo étnico (y en cuáles no), también ha favorecido el acceso a distintos campos como el institucional y el educativo, para obtener beneficios a los que otros grupos en situación marginal y de pobreza no pueden acceder de manera fácil. Este hecho es un elemento fundamental en la forma en que se han organizado socialmente las comunidades indígenas en el espacio urbano.

\section{REFLEXIONES FINALES}

Se han mostrado los elementos implicados y el proceso a través del cual se ha construido el espacio social de los indígenas en la ciudad. Para su conformación, la participación de las instituciones gubernamentales y grupos proindígenas ha sido clave, como también lo ha sido el involucramiento de los indígenas como actores sociales. Lo que define a la espacialidad indígena y la hace diferente son los sujetos que han confluido, los intereses y poderes que confluyen en cada región. No se puede afirmar que permanecerá intacta con el paso del tiempo, al contrario, cambiará y se reconstruirá dependiendo del contexto socioespacial que se presente.

Las acciones, hechos e iniciativas que han surgido desde este conjunto de actores externos sin duda han impactado para que los indígenas sean visibles, para que la sociedad en general conozca sobre este sector de la población. De cierta manera, esto ha beneficiado sólo a ciertas comunidades indígenas, las que son visibles y que viven de manera congregada, por ejemplo en el acceso a servicios 
educativos (escuelas, becas); información sobre la salud; oportunidades para acceder o mejorar la vivienda; información sobre programas sociales (como Oportunidades). Pero esto no indica que se haya dado una inclusión social de los indígenas, entendida ésta como el proceso de reconocimiento de los derechos de los indígenas por parte del Estado, donde se respeten sus prácticas culturales, en todos los sentidos, así como su inserción social, económica, política y residencial de una manera digna, como cualquier otro ciudadano que radica en la metrópoli regia.

$\mathrm{Al} \mathrm{revindicar} \mathrm{la} \mathrm{retórica} \mathrm{de} \mathrm{inclusión} \mathrm{e} \mathrm{interacción} \mathrm{que} \mathrm{el} \mathrm{espacio}$ público debe representar, los grupos excluidos han logrado argumentar a favor de sus derechos como parte del público activo. Las representaciones espaciales se vuelven sitios estratégicos para la lucha de la ciudadanía. Ésta no sólo se puede pensar como una concesión del estado, sino que es activa y constantemente construida por medio de la identificación con una variedad de grupos o sistemas de valores que no están basados en las identidades limitadas o predeterminadas. De esta manera las comunidades que se movilizan en territorio nacional reclaman sus derechos como pueblos indígenas. En este sentido no sólo se busca la inserción social en la ciudad sino también la ciudadanía étnica, entendida como "el reclamo de mantener la identidad y una organización societal diferenciada dentro de un estado, que a su vez no sólo debe reconocer sino proteger y sancionar jurídicamente tales diferencias"(De la Peña 1999, 11). No sólo es la movilidad geográfica del sujeto, sino de sus valores, cultura, signos y organizaciones, que llevan de un lugar a otro y que lo reterritorializan en uno o más espacios al mismo tiempo (Besserer 2009). La inserción de los indígenas al AMM no es sólo económica o física sino es una inserción compleja en busca de la igualdad y equidad de derechos, los mismos que los ciudadanos regios tienen, pero enmarcados en la diferencia de ciudadanía cultural. La inserción es un proceso que aún sigue en negociación entre actores indígenas y no indígenas, no es una búsqueda de la ciudadanía de papeles y derechos legales, sino una ciudadanía de pertenencia, de membresía a un nuevo espacio (Rosaldo 2007).

Los indígenas, para insertarse en el espacio social urbano, han tenido que utilizar herramientas para hacerlo. Una de ellas son las 
asociaciones indígenas y las relaciones que tejen con otros actores sociales. Si bien, son visibles ante el Estado y el gobierno, esto no indica su aceptación o su inclusión social en la ciudad, pues aún son vistos como un problema y no como un sector de la población que tiene problemas determinados y que necesitan ser abordados. No basta con apoyarlos satisfaciendo las necesidades básicas, como vivienda, salud, alimentación, educación, de manera asistencialista, que sólo reproduce un modelo paternalista, sino más bien, trabajar para insertarlos en trabajos dignos, ofreciéndoles educación y la oportunidad de ascenso social.

El cambio de residencia de los grupos indígenas es un acto significativo que llega a impactar en la etnicidad y organización social de las comunidades de origen, sin embargo, el lugar receptor, en este caso el AMM, también entra en un proceso de cambios y transformaciones generadas por la presencia de este nuevo sector de la población. El espacio receptor no sólo contiene a la sociedad, no es un observador pasivo, sino que también es un actor más en la configuración de la espacialidad.

Es precisamente este punto en el cual el presente trabajo se diferencia de los realizados en otras disciplinas que han abordado el tema de indígenas en la ciudad. En el presente se ha analizado cómo se construye un espacio social y no sólo quiénes interactúan, cuáles han sido los cambios físicos en la ciudad y cómo es el tipo de relaciones entre los indígenas y la sociedad mayoritaria, todo ello para explicar la organización social de los indígenas en el AMM.

\section{REFERENCIAS BIBLIOGRÁFICAS}

Aceves González, Francisco de Jesús, "La territorialidad. Punto nodal en la intersección espacio urbano-procesos de comunicación-movimiento social" en Comunicación y Sociedad, núm. 30, mayo-agosto 1997, Universidad de Guadalajara, 275-301.

Arizpe, Lourdes, Indígenas en la ciudad de México. El caso de las Marías, México, SepSetentas, 1975, 7-36.

Barabas, Alicia, "Los migrantes indígenas de Oaxaca en Estados Unidos: fronteras, asociaciones y comunidades” en Laura Velas- 
co, coord., Migración, fronteras e identidades étnicas trasnacionales, El Colegio de la Frontera Norte, Miguel Ángel Porrúa, 2008, 171-193.

BARrows, Harlan, "La geografía como ecología humana" en Josefina Gómez Mendoza, El pensamiento geográfico, Madrid, Alianza, 1982. Besserer, Federico, "Estudios trasnacionales y ciudadanía trasnacional" en Gail Mummert, ed., Fronteras fragmentadas, 2da. edición, Zamora, El Colegio de Michoacán, CIDEM, 2009, 153-167.

Bozzano, Horacio, Territorios posibles. Procesos, lugares y actores, Buenos Aires, Editorial Lumiere, 2009.

Buttimer, Anne, "Grasping the Dynamism of Lifeworld”, en Annals of the Association of American Geographique, vol. 66, núm. 2, 1976, 277-292.

BLANCO, Jorge, "Espacio y territorio: Elementos teóricos-conceptuales implicados en el análisis geográfico”, en María Victoria Fernández Caso y Raquel Guverich, coords., Geografía. Nuevos temas, nuevas preguntas. Un temario para su enseñanza, Editorial Biblio, 2007, 39-64.

Camus, Manuela, "Espacio y etnicidad: Sus multiples dimensiones", en Papeles de Población Indígena, octubre-diciembre, núm. 22, Toluca, Universidad Autónoma del Estado de México, 1999, 161-197.

Chávez Torres, Martha, "Espacios de confluencia. Geografía humana y ciencias sociales" en Martha Chávez Torres, Octavio M. González Santana y María del Carmen Ventura Patiño, eds., Geografía humana y ciencias sociales. Una relación reexaminada, Zamora, El Colegio de Michoacán, 2009, 11-30.

Clark Alfaro, Víctor, Mixtecos en Frontera, Comisión Nacional para el Desarrollo de los Pueblos Indígenas (CDI), 2008.

DíAz, Adela, "La Alameda de Monterrey: espacio estratégico de encuentro de los migrantes indígenas de la Huasteca” en Séverine, Durin, coord., Entre luces y sombras. Miradas sobre los indigenas en el área metropolitana de Monterrey, México, Publicaciones de la Casa Chata, Ciesas, 2008, 139-166.

De la Peña, Guillermo, "Territorio y ciudadanía étnica en la nación globalizada”, en Desacatos, núm. 001, México, Ciesas, 1999.

Durin, Séverine, “¿Una educación indígena intercultural para la 
ciudad? El Departamento de Educación Indígena en Nuevo León”, en Frontera Norte, El Colegio de la Frontera Norte, juliodiciembre, núm. 038, 2007, 63-91.

, Entre luces y sombras. Miradas sobre los indígenas en el área metropolitana de Monterrey, México, Publicaciones de la Casa Chata, Ciesas, 2008.

Durin, Séverine, Rebeca Moreno y Cecilia Sheridan, "Rostros desconocidos. Perfil sociodemográfico de las indígenas en Monterrey", en Trayectorias, Universidad Autonoma de Nuevo León, enero-abril, año Ix, núm. 32, 2007, 29-42.

Durin, Séverine y Nicolás Pernet, "Redes sociales, etnicidad y recomposición de espacios residenciales en familias mazahuas de Temascalcingo en Monterrey" en Lilia Palacios, ed., Cuando México enfrenta la globalización. Permanencias y cambios en el área metropolitana de Monterrey, Universidad Autónoma de Nuevo León, El Colegio de la Frontera Norte, 2010, 11-129.

FARET, Laurent, "Mobilite spatialite et territorialite. De la diversite des forms de construction du rapport aux lieux", Seminarie PRISMA, Toulouse, 10 y 11 mayo, 2001.

Fernández Christlieb, Federico, “QQuién estudia ese espacio? Una reflexión sobre la geografía y los intereses de las ciencias sociales" en Martha Chávez Torres, Octavio M. González Santana y María del Carmen Ventura Patiño, eds., Geografía humana y ciencias sociales. Una reflexión reexaminada, Zamora, El Colegio de Michoacán, 2009, 07-130.

Fleurr, Sonia, "Política Social, exclusión y equidad en America Latina en los años 90". Trabajo presentado en el seminario sobre política social, exclusión y equidad en Venezuela durante los ańos noventa. Balance y perspectiva en Caracas, mayo 1998, Buenos Aires, Centro de documentación en Políticas Sociales, Documentos/15, 1999.

Forni, P., M. Siles, L. Barreiro, “¿Qué es el capital social y cómo analizarlo en contexto de exclusión social y pobreza? Estudio de caso en Buenos Aires Argentina”, en Research Report, núm. 34, diciembre, Julian Samora Research Institute, Michigan State University, 2004, 1-16. 
Frémont, Armand, ¿Aimez-vous la géographie?, París, Flammarion, 2005.

García Tello, Diana Patricia, "Mixtecos regios. Organización socioespacial e inserción de un grupo mixteco al área metropolitana de Monterrey", Tesis de Maestría en Geografía Humana, Zamora, El Colegio de Michoacán, 2010.

Granados, A., "Las nuevas zonas de atracción de migrantes indígenas en México" en Investigaciones Geográficas, Boletín del Instituto de Geografía, UNAM, núm. 58, 2005, 140-147.

Hiernaux, Daniel-Nicolás, Metrópoli y etnicidad. Los indígenas en el valle de Chalco, El Colegio Mexiquense, FonCA, H. Ayuntamiento Valle de Chalco Solidaridad 1997-2000, Dirección de Cultura, 2000.

Leal Sorcia, Olivia, Indigenas urbanos: Temas y enfoques recientes, Zamora, Doctorado Tutorial en Ciencias Sociales, El Colegio de Michoacán, febrero, 2010.

Lestage, Françoise, "Relaciones familiares y de género en redefinición" en Gail Mummert, ed., Fronteras fragmentadas, Zamora, El Colegio de Michoacán, CIDEM, 2009.

, "La adaptación del migrante, un compromiso entre varias representaciones de sí mismo", en Scripta Nova. Revista Electrónica de Geografía y Ciencias Sociales, núm. 94 (16), Universidad de Barcelona, 2001, 1-11.

Lindón, Alicia, Miguel Ángel Aguilar y Daniel Hiernaux, Lugares e imaginarios en la metrópolis, Anthropos, UAM, México, 2006.

Martínez Casas, Regina y Guillermo de la Peña, "Migrantes y comunidades morales: resignificación, etnicidad y redes sociales en Guadalajara”, en Revista de Antropología Social de la Universidad Complutense de Madrid, núm. 13, 2004, 217-251.

Mayer, H. M y C. F. Kohn, Readings in Urban Geography, Chicago, The University of Chicago Press, 1959.

Mendoza, Cristóbal, "Geografía de la Población” en Daniel Hiernaux y Alicia Lindón, dir., Tratado de geografía humana, México, Universidad Autónoma Metropolitana, Antrhopos, 2006, 147-169.

NovoA, Édgar, Un espacio para el espacio social: debates y perspectivas contemporáneas, Colombia, 2006. 
Oenmichen, Cristina, "Espacio urbano y segregación espacial en la ciudad de México" en Papeles de Población, núm. 28, Toluca, Universidad Autónoma del Estado de México, abril-junio, 2011, 181-197.

Ortega Valcárcel, José, "La geografía para el siglo XXI”, en Joan Romero, Geografía humana. Procesos, riesgos e incertidumbres en un mundo globalizado, Barcelona, Ariel, 2007, 25-64.

Ortiz Álvares, María Inés, La población hablante de lengua indigena en México, México, Temas Selectos de Geografía, Instituto de Geografía, UNAM, 2005.

Paniagua, Ángel, "Geografía rural” en Daniel Hiernaux y Alicia Lindón, dir., Tratado de geografía humana, México, Universidad Autónoma Metropolitana, Antrhopos, 2006, 70-83.

Pernet, Nicolás, Indiens et Urbains. Géographie d'un groupe ethnique Dans l'Aire Métropolitane de Monterrey. Le cas de Mazahuas de Santiago Coachochitlán, Master Géographie Université de Provence, 2009.

RosAldo, Renato, "Multiculturalidad y ciudadanía", ponencia magistral presentada en el Coloquio Internacional Ciudades Multiculturales de América. Migraciones, Relaciones Interetnicas, Etnicidad, octubre, Monterrey, 2007.

Talavera Durón, Luis Francisco, Los pueblos de madera y la gente de lluvia. Etnicidad urbana. Purépechas y mixtecos en la Zona Metropolitana de Guadalajara, Tesis de Maestría en Antropología Social, Ciesas, Guadalajara, Jalisco, 2006.

Tuan, Yi Fu, "Humanistic Geography", en Annals of the Association of American Geographers, vol. 70, núm. 2, 1976.

Urbalejo, Lorenia,"La ciudad como espacio vivido: Mixtecos de Guerrero en Tijuana", Tesis de Maestría en Geografía Humana, Zamora, El Colegio de Michoacán, 2009.

Velasco Ortiz, Laura, Migración, fronteras e identidades étnicas trasnacionales, El Colegio de La Frontera Norte, Miguel Ángel Porrúa, 2008.

FECHA DE RECEPCIÓN DEL ARTículo: 21 de noviembre de 2011 FECHA DE RECEPCIÓN DE LA VERSIÓN FINAL: 16 de marzo de 2012 